International Journal of Pure and Applied Mathematics

Volume 96 No. 4 2014, 507-522

ISSN: 1311-8080 (printed version); ISSN: 1314-3395 (on-line version)

url: http://www.ijpam.eu

doi: http://dx.doi.org/10.12732/ijpam.v96i4.6

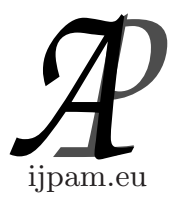

\title{
NUMERICAL SIMULATION OF NATURAL CONVECTION \\ IN A PARTIALLY COOLED SQUARE ENCLOSURE FILLED WITH POROUS MEDIUM
}

\author{
Wiratchada Kalaoka ${ }^{1}$, Supot Witayangkurn ${ }^{2} \S$ \\ ${ }^{1,2}$ Department of Mathematics \\ Faculty of Science \\ Khon Kaen University \\ Khon Kaen 40002, THAILAND \\ ${ }^{2}$ Center of Excellence in Mathematics \\ Commission on Higher Education \\ Si Ayutthaya Road, Bangkok, 10400, THAILAND
}

\begin{abstract}
The present paper numerically studies natural convection in a partially cooled square enclosure filled with a porous medium. One of the enclosure walls is heated while the middle opposite wall is partially cooled. The remaining walls are adiabatic. The governing equations which are continuity, momentum and energy equations are solved using finite element method with FlexPDE 6.20 Professional. The relevant parameters for computations are Darcy numbers $\left(D a=10^{-5}-10^{-3}\right)$, Rayleigh numbers $\left(R a=10^{4}-10^{6}\right)$, Prandtl numbers $(\operatorname{Pr}=0.70-10)$ and cold length $(D=0.50)$. The numerical results are present in terms of isotherms, streamlines and heatlines. It is found that varied Darcy and Rayleigh numbers can lead to difference temperature flow and heat fields. The results of this study can be use in the thermal insulation of buildings and cooling systems of electronic devices.
\end{abstract}

Received: May 3, 2014

(c) 2014 Academic Publications, Ltd. url: www.acadpubl.eu

${ }^{\S}$ Correspondence author 
AMS Subject Classification: 65M60, 76D05, 76R10, 76S05, 80A20

Key Words: finite element method, natural convection, partially cooled, porous medium

\section{Introduction}

The fluid motion is caused by buoyancy forces that result from the density variations due to variations of temperature in the fluid. This phenomenon is known as natural convection. The problem of natural convection in enclosures has been studied extensively $[1,2,3,4,5]$. This is due to wide application areas in scientific and engineering applications such as thermal insulation of buildings [6], efficient design of solar system [7], food storage [8], cooling of electronic equipments [9], etc.

In the literature, there are several studies on natural convection inside a porous square enclosure. Mealey and Merkin [10] investigated the steady natural convective flow in a porous square cavity with internal heat generation. They found that boundary layers develop on the side walls with a weak eddy flow in the central region for higher values of Rayleigh number. Then, Costa et al. [11] examined the effects of a magnetic field on natural convection of electrically conducting fluids contained in differentially heated porous square cavities. They concluded that suppresion of the natural convection increases for larger values of the magnetic field. The steady natural convection in a porous square enclosure with the non-Darcy model has been introduced by Saeid and Pop [12]. They observed that the strength of fluid motion decreases with increasing the inertial effects parameter. Natural convection flow in a porous square cavity for various thermal boundary conditions has been studied by Basak et al. [13]. Their studies indicated that the heat transfer is primarily due to conduction for low Darcy number irrespective of Rayleigh and Prandtl numbers. Mahapatra et al. [14] analyzed the influence of thermal radiation on natural convection flow in a lid-driven square enclosure filled with Darcy-Forchheimer porous medium. They found that the temperature distribution decreases with an increase in the Rayleigh number.

For the study on natural convection in partially cooled enclosures, Nithyadevi et al. [15] examined the effect of aspect ratio on natural convection in a rectangular enclosure with partially thermally active vertical walls. They reported that the heat transfer rate increases with increasing the aspect ratio of the enclosure. Varol et al. [16] investigated the natural convection in a right-angle porous trapezoidal enclosure with inclined wall partially cooled. They con- 
cluded that aspect ratio of the cavity affects the length of convection cell. The diffusion and convection heat transport for natural convection in a differentially heated square cavity has been visualized by Mobedi et al. [17]. Their results showed that the maximum absolute value of heat function may be an appropriate parameter for determination of the convection strength. Further, Oztop [18] presented the natural convection in a partially cooled and inclined rectangular cavity filled with a porous medium. It is found that inclination angle is the dominant parameter on heat transfer and fluid motion. El-refaee et al. [19] studied the laminar natural convection in partially cooled tilted cavities. They concluded that the effects of aspect ratio and tilt angle on the rate of heat transfer becomes less significant with smaller values of opening ratio. Natural convection in a porous square cavity due to partial heating and cooling at side walls has been analyzed by Alam et al. [20]. They concluded that increasing Darcy number increases the flow strength in the cavity. Natural convection in a square cavity with partially thermally active side walls has been considered by Nithyadevi et al. [21]. They found that the heat transfer increases with increasing Grashof number. Pakdee and Rattanadecho [22] introduced the natural convection in a partially cooled square cavity filled with a porous medium. Their studies indicated that the intensity of fluid flow is stronger for higher Darcy numbers.

The objective of this paper is to investigate the temperature distribution, fluid flow and heat flow in a porous square enclosure with partially cooled on the middle right side wall. In this work, FlexPDE 6.20 Professional is a software package to solve governing equations, using finite element method. Numerical results are obtained and illustrated by isotherms, streamlines and heatlines within the cavity. The interested parameters are Darcy numbers $\left(10^{-5} \leq D a \leq\right.$ $\left.10^{-3}\right)$, Rayleigh numbers $\left(10^{4} \leq R a \leq 10^{6}\right)$, Prandtl numbers $(0.70 \leq \operatorname{Pr} \leq$ $10)$ and cold length $(D=0.50)$. Main attention is focused on the effects of Darcy and Rayleigh numbers. The paper is organized as follows. The problem definition and mathematical formulation are presented in Section 2, followed by results and discussion in Section 3. Conclusions are given in Section 4 .

\section{Problem Definition and Mathematical Formulation}

A schematic of two-dimensional square enclosure filled with a fluid-saturated porous medium with the length $L$ as shown in Fig. 1. The left wall is heated with a constant temperature $T_{h}$, the right wall is partially cooled with a constant temperature $T_{c}$, where $T_{h}>T_{c}$ and the cooled portion is located at the middle of 


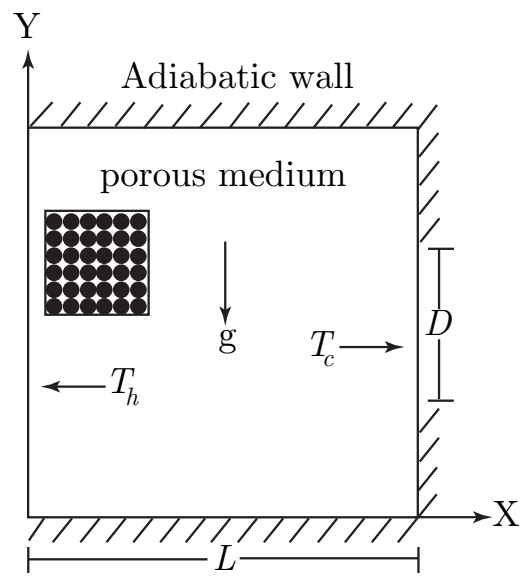

Figure 1: Physical model with coordinates.

the right wall with the length $D$. The other walls of the enclosure are insulated.

In this work, the fluid-saturated porous medium is assumed to be incompressible, Newtonian and the flow is laminar. The physical properties are assumed to be constant except the density in buoyancy term. The governing equations for two-dimensional natural convection flow in a porous square enclosure using the continuity, momentum and energy equations [23] can be stated as:

$$
\begin{aligned}
\frac{\partial u}{\partial x}+\frac{\partial u}{\partial y}= & 0 \\
u \frac{\partial u}{\partial x}+v \frac{\partial u}{\partial y}= & -\frac{1}{\rho} \frac{\partial p}{\partial x}+\nu\left(\frac{\partial^{2} u}{\partial x^{2}}+\frac{\partial^{2} u}{\partial y^{2}}\right)-\frac{\nu}{K} u \\
u \frac{\partial v}{\partial x}+v \frac{\partial v}{\partial y}= & -\frac{1}{\rho} \frac{\partial p}{\partial y}+\nu\left(\frac{\partial^{2} v}{\partial x^{2}}+\frac{\partial^{2} v}{\partial y^{2}}\right)-\frac{\nu}{K} v \\
& +g \beta\left(T-T_{c}\right), \\
u \frac{\partial T}{\partial x}+v \frac{\partial T}{\partial y}= & \alpha\left(\frac{\partial^{2} T}{\partial x^{2}}+\frac{\partial^{2} T}{\partial y^{2}}\right)
\end{aligned}
$$

with the boundary conditions

$u(x, 0)=u(x, L)=u(0, y)=u(L, y)=0$,

$v(x, 0)=v(x, L)=v(0, y)=v(L, y)=0$, 
$\frac{\partial T}{\partial y}(x, 0)=\frac{\partial T}{\partial y}(x, L)=0, T(0, y)=T_{h}$,

$\frac{\partial T}{\partial x}(L, y)=0$ when $0 \leq y \leq \frac{L}{4}$,

$T(L, y)=T_{c}$ when $\frac{L}{4} \leq y \leq \frac{3 L}{4}$,

$\frac{\partial T}{\partial x}(L, y)=0$ when $\frac{3 L}{4} \leq y \leq L$.

The above governing equations are transformed to dimensionless form by using the following change of variables:

$X=\frac{x}{L}, \quad Y=\frac{y}{L}, \quad U=\frac{u L}{\alpha}, \quad V=\frac{v L}{\alpha}, \quad P=\frac{p L^{2}}{\rho \alpha^{2}}, \quad \operatorname{Pr}=\frac{\nu}{\alpha}$,

$D a=\frac{K}{L^{2}}, \quad \theta=\frac{T-T_{c}}{T_{h}-T_{c}}, \quad R a=\frac{g \beta\left(T_{h}-T_{c}\right) L^{3} P r}{\nu^{2}}$.

The governing equations (1)-(4) are reduced to the following non-dimensional form:

$$
\begin{aligned}
\frac{\partial U}{\partial X}+\frac{\partial U}{\partial Y}= & 0 \\
U \frac{\partial U}{\partial X}+V \frac{\partial U}{\partial Y}= & -\frac{\partial P}{\partial X}+\operatorname{Pr}\left(\frac{\partial^{2} U}{\partial X^{2}}+\frac{\partial^{2} U}{\partial Y^{2}}\right)-\frac{P r}{D a} U \\
U \frac{\partial V}{\partial X}+V \frac{\partial V}{\partial Y}= & -\frac{\partial P}{\partial Y}+\operatorname{Pr}\left(\frac{\partial^{2} V}{\partial X^{2}}+\frac{\partial^{2} V}{\partial Y^{2}}\right)-\frac{\operatorname{Pr}}{D a} V \\
& +\operatorname{RaPr} \theta \\
U \frac{\partial \theta}{\partial X}+V \frac{\partial \theta}{\partial Y}= & \frac{\partial^{2} \theta}{\partial X^{2}}+\frac{\partial^{2} \theta}{\partial Y^{2}} .
\end{aligned}
$$

To eliminating the pressure $P$, we use the penalty finite element method with a penalty parameter [24] such that

$$
P=-\gamma\left(\frac{\partial U}{\partial X}+\frac{\partial V}{\partial Y}\right)
$$

Typical values of $\gamma$ that yield consistent solutions are $10^{7}$. Substituting (9) into (6) and (7), they are reduced to

$$
U \frac{\partial U}{\partial X}+V \frac{\partial U}{\partial Y}=\gamma \frac{\partial}{\partial X}\left(\frac{\partial U}{\partial X}+\frac{\partial V}{\partial Y}\right)+\operatorname{Pr}\left(\frac{\partial^{2} U}{\partial X^{2}}+\frac{\partial^{2} U}{\partial Y^{2}}\right)
$$




$$
\begin{aligned}
& -\frac{P r}{D a} U \\
& U \frac{\partial V}{\partial X}+V \frac{\partial V}{\partial Y}=\gamma \frac{\partial}{\partial Y}\left(\frac{\partial U}{\partial X}+\frac{\partial V}{\partial Y}\right)+\operatorname{Pr}\left(\frac{\partial^{2} V}{\partial X^{2}}+\frac{\partial^{2} V}{\partial Y^{2}}\right) \\
& -\frac{\operatorname{Pr}}{D a} V+R a \operatorname{Pr} \theta
\end{aligned}
$$

with the transformed boundary conditions

$U(X, 0)=U(X, 1)=U(0, Y)=U(1, Y)=0$,

$V(X, 0)=V(X, 1)=V(0, Y)=V(1, Y)=0$,

$\frac{\partial \theta}{\partial Y}(X, 0)=\frac{\partial \theta}{\partial Y}(X, 1)=0, \theta(0, Y)=1$,

$\frac{\partial \theta}{\partial X}(1, Y)=0$ when $0 \leq Y \leq 0.25$,

$\theta(1, Y)=0$ when $0.25 \leq Y \leq 0.75$,

$\frac{\partial \theta}{\partial X}(1, Y)=0$ when $0.75 \leq Y \leq 1$.

The stream function $(\psi)$ for two dimensional flows is obtained from velocity components $U$ and $V$ [25]. The relationships between stream function, $\psi$ and velocity components are

$$
U=\frac{\partial \psi}{\partial Y} \quad \text { and } \quad V=-\frac{\partial \psi}{\partial X}
$$

From the above equation we can obtained the following relation:

$$
\frac{\partial^{2} \psi}{\partial X^{2}}+\frac{\partial^{2} \psi}{\partial Y^{2}}=\frac{\partial U}{\partial Y}-\frac{\partial V}{\partial X}
$$

The no-slip condition is valid at all boundaries as there is no cross flow. The boundary condition for stream function is $\psi=0$ for all boundaries. The sign convection is as follows. Negative sign of $\psi$ denotes clockwise circulation and anti-clockwise circulation is represented by positive sign of $\psi$.

The heat flow in the enclosure is illustrated by using the heat function (П) obtained from conductive heat fluxes $\left(-\frac{\partial \theta}{\partial X},-\frac{\partial \theta}{\partial Y}\right)$ as well as convective heat fluxes $(U \theta, V \theta)$. The heat function satisfies the steady energy balance equation (8) $[26]$ such that

$$
\frac{\partial \Pi}{\partial Y}=U \theta-\frac{\partial \theta}{\partial X},
$$




$$
-\frac{\partial \Pi}{\partial X}=V \theta-\frac{\partial \theta}{\partial Y}
$$

which yield a single equation

$$
\frac{\partial^{2} \Pi}{\partial X^{2}}+\frac{\partial^{2} \Pi}{\partial Y^{2}}=\frac{\partial}{\partial Y}(U \theta)-\frac{\partial}{\partial X}(V \theta) .
$$

The boundary conditions for heat function are:

$\frac{\partial \Pi}{\partial X}=1$ (for heated wall),

$\frac{\partial \Pi}{\partial X}=0$ (for cooled portion),

$\Pi=0 \quad$ (for adiabatic wall).

Using the above definition of the heat function, the negative sign of $\Pi$ represent clockwise heat flow while the positive sign of $\Pi$ refers anti-clockwise heat flow.

\section{Results and Discussion}

The numerical results and discussion for the problem of natural convection in a porous square enclosure with partially cooled from middle right vertical wall are presented in this section. To analyze the numerical solutions, the procedure mentioned previously is coded into FlexPDE 6.20 Professional which is based on the finite element method. This work is performed for different parameters, Darcy numbers, Rayleigh numbers, Prandtl numbers and cold length. Effects of Darcy and Rayleigh numbers are considered. The temperature, flow and heat fields in the enclosure are displayed in terms of isotherms, streamlines and heatlines.

\subsection{Effect of Darcy Numbers}

Isotherms, streamlines and heatlines are plotted in Figs. 2-4 for different Darcy numbers such as $D a=10^{-5}, 10^{-4}$ and $10^{-3}$ while Rayleigh number, Prandtl number and cold length are fixed at $R a=10^{6}, \operatorname{Pr}=0.70$ and $D=0.50$, respectively.

The isotherms are smooth curves for all values of the Darcy numbers considered. For $D a=10^{-5}$ which is the smallest Darcy number in the present study. The isotherms show almost parallel distribution to the vertical walls as given in Fig. 2(a). As $D a$ increases to $10^{-4}$, the isotherms move toward to 


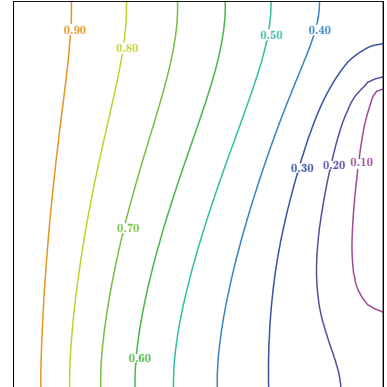

(a)

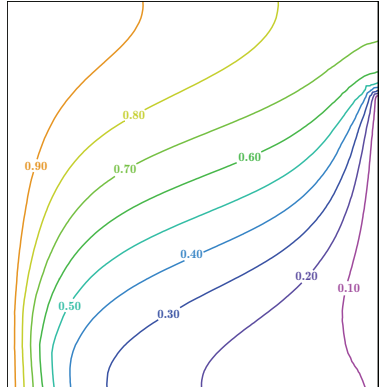

(b)

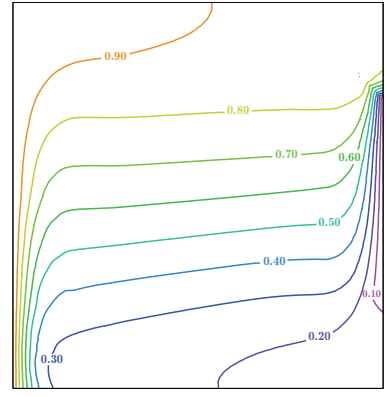

(c)

Figure 2: Isotherms with $R a=10^{6}, \operatorname{Pr}=0.70, D=0.50$ for (a) $D a=10^{-5}$ (b) $D a=10^{-4}$ and (c) $D a=10^{-3}$.

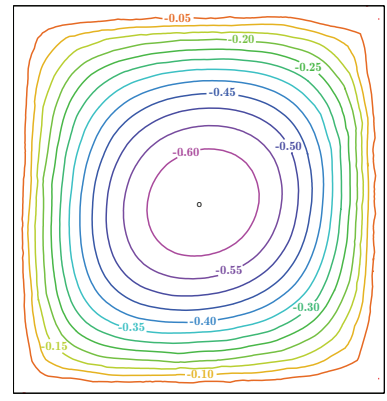

(a)

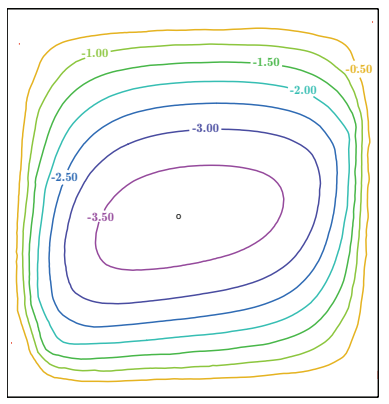

(b)

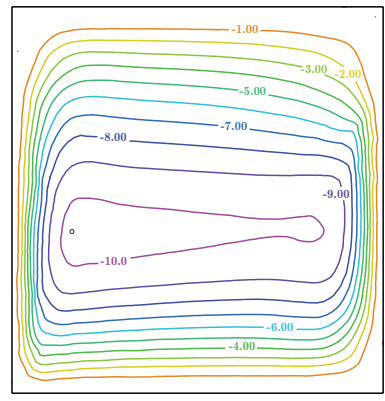

(c)

Figure 3: Streamlines with $R a=10^{6}, \operatorname{Pr}=0.70, D=0.50$ for (a) $D a=10^{-5}$ (b) $D a=10^{-4}$ and (c) $D a=10^{-3}$.

the right wall. As seen from Fig. 2(c), the isotherms are almost parallel to the horizontal walls when $D a$ increases to $10^{-3}$.

The flow consists of a single cell in clockwise rotating direction for all values of the parameters considered. At $D a=10^{-5}$, the streamlines are round shape and the convective motion in the cavity is found to be weak as seen from the maximum absolute value of the stream function with $|\psi|_{\max }=0.60$. When $D a$ increases to $10^{-4}$, the main vortex of the streamlines expands in size and the maximum absolute value of the stream function with $|\psi|_{\text {max }}=3.50$ can be observed in Fig. 3(b). For highest value of Darcy number, i.e. $D a=10^{-3}$, 


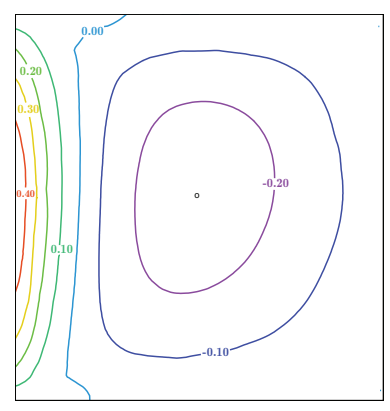

(a)

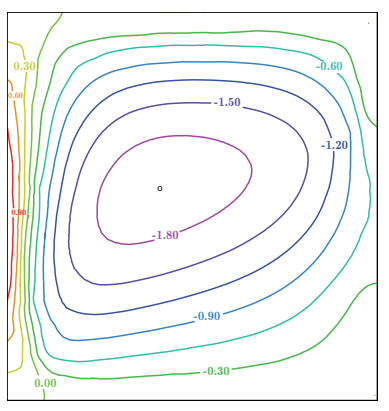

(b)

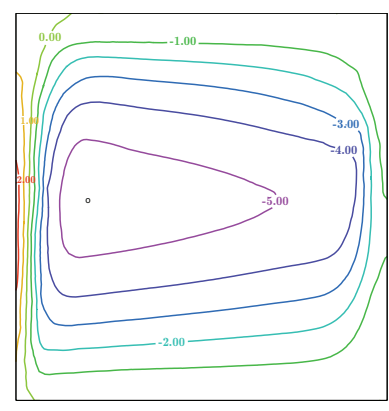

(c)

Figure 4: Heatlines with $R a=10^{6}, \operatorname{Pr}=0.70, D=0.50$ for (a) $D a=10^{-5}$ (b) $D a=10^{-4}$ and (c) $D a=10^{-3}$.

the fluid circulation elongates in the cavity and the intensity of fluid motion increases with $|\psi|_{\max }=10$ due to increasing of convection mode of heat transfer.

Heat distribution occurring in the enclosure is visualized by heatlines. In Figs. 4(a)-4(c), the heatlines are dispersed near the heated side wall and it takes negative values due to the clockwise rotation of convective heat. It is seen that at lower value of Darcy number $\left(D a=10^{-5}\right)$, the magnitude of the heat function are small (see Fig. 4(a)), indicating a slow convective heat flow. As $D a$ increases from $10^{-4}$ to $10^{-3}$, the convective cell of heatlines becomes bigger and the strength of heat function is found to be stronger. It is noted that, $|\Pi|_{\max }=1.80$ for $D a=10^{-4}$ while $|\Pi|_{\max }=5$ for $D a=10^{-3}$.

\subsection{Effect of Rayleigh Numbers}

Figs. $5-7$ present isotherms, streamlines and heatlines for various values of Rayleigh number such as $R a=10^{4}, 10^{5}$ and $10^{6}$ and $D a=10^{-4}, \operatorname{Pr}=10$ and $D=0.50$.

It may be noted that, isotherms are smooth lines for all values of Rayleigh number considered. At low Rayleigh number $\left(R a=10^{4}\right)$, the isotherms are distributed almost parallel to the side walls as given in Fig. 5(a). As $R a$ increases from $10^{5}$ to $10^{6}$, isotherm patterns are similar to the cases of Darcy number with $D a=10^{-5}-10^{-4}$, the isotherms are moved to almost parallel to the horizontal walls.

For all values of the parameters considered, a clockwise convection cell with negative values of the stream function in the enclosure exists. At $R a=10^{4}$, 


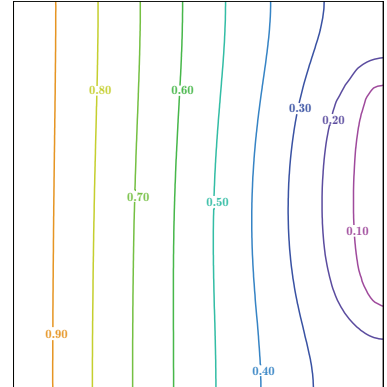

(a)

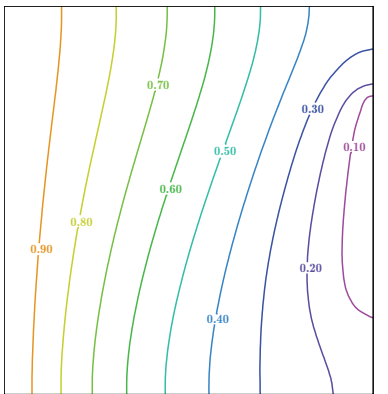

(b)

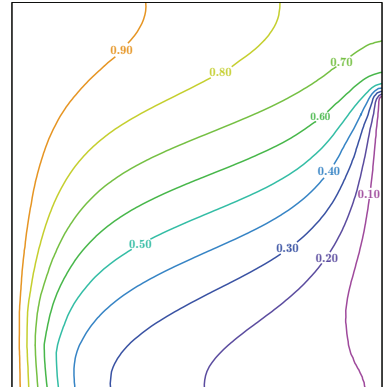

(c)

Figure 5: Isotherms with $D a=10^{-4}, \operatorname{Pr}=10, D=0.50$ for (a) $R a=10^{4}$ (b) $R a=10^{5}$ and (c) $R a=10^{6}$.

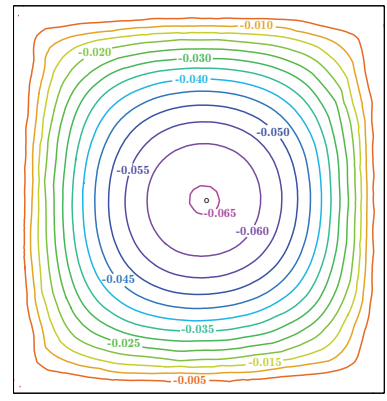

(a)

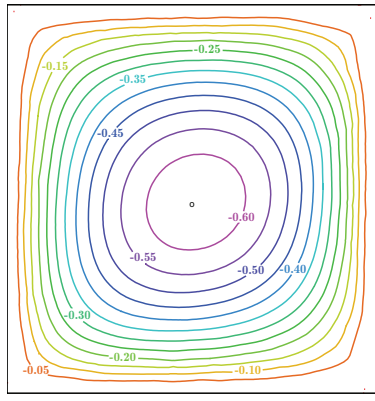

(b)

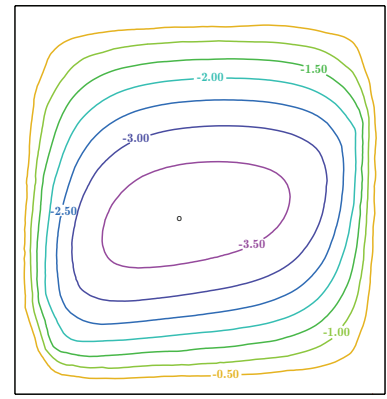

(c)

Figure 6: Streamlines with $D a=10^{-4}, \operatorname{Pr}=10, D=0.50$ for (a) $R a=10^{4}$ (b) $R a=10^{5}$ and (c) $R a=10^{6}$.

circle shape was formed in the enclosure. The magnitude of the streamlines are small $\left(|\psi|_{\max }=0.065\right)$ indicating a very slow convective fluid flow and strong conduction heat transfer can be observed in Fig. 6(a). When $R a$ increases to $10^{5}$, the streamlines show qualitatively similar features to the case of $D a=10^{-5}$ and the intensity of fluid motion increases with $|\psi|_{\max }=0.60$. Similar pattern of streamlines were observed at $D a=10^{-4}$ (see Fig. 3(c)) and the maximum absolute value of stream function is 3.50 with an increase in $R a$ to $10^{6}$.

As seen from Fig. 7(a), the heatlines are smoothly distributed near the left wall for $R a=10^{4}$. Enhanced natural convective heat transfer in the cavity is 


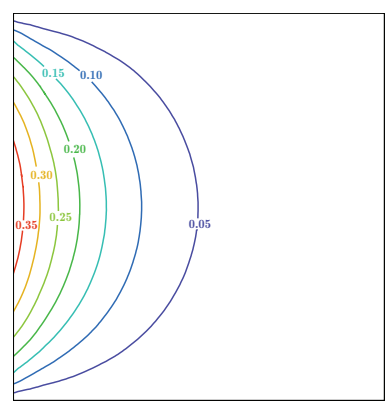

(a)

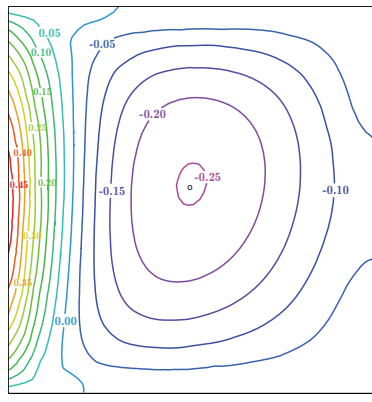

(b)

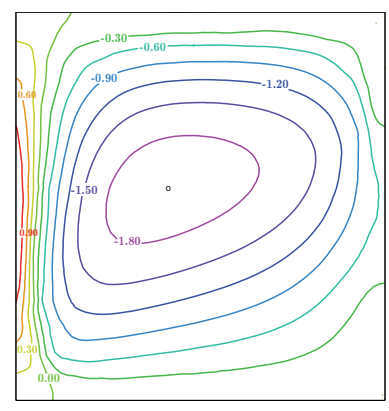

(c)

Figure 7: Heatlines with $D a=10^{-4}, \operatorname{Pr}=10, D=0.50$ for (a) $R a=10^{4}$ (b) $R a=10^{5}$ and (c) $R a=10^{6}$.

clearly displayed by a clockwise rotating cell of heatlines when $R a$ increases from $10^{5}$ to $10^{6}$. It is observed that the maximum absolute value of heat function with $|\Pi|_{\max }=0.25$ as $R a$ increases to $10^{5}$. For highest value of Rayleigh number $\left(R a=10^{6}\right)$, heatlines patterns are qualitatively identical to $D a=10^{-4}$ case, the heatlines circulation cell grows in size. The maximum absolute value of heat function is 1.80 as shown in Fig. 7(c).

\section{Conclusions}

Natural convection in a porous square enclosure with the left wall is heated, the middle of the right wall is partially cooled and the others walls are adiabatic, has been analyzed numerically using FlexPDE 6.20 Professional which is based on the finite element method. The main parameters of interest are Darcy numbers, Rayleigh numbers, Prandtl numbers and cold length. The effects of Darcy and Rayleigh numbers are examined in this work. The main conclusions can be listed as follows:

(i) Both increasing the values of Darcy and Rayleigh numbers, the temperature distribution in the cavity is almost parallel to horizontal walls due to convection dominant heat transfer.

(ii) A single flow circulation cell is obtained in the clockwise direction for all values of the parameters considered. 
(iii) The strength of buoyant convection flow increases with increasing Darcy and Rayleigh number and as a result the maximum absolute value of heat function increases.

(iv) There is no a single circulation cell of heatlines for low value of Rayleigh number $\left(R a=10^{4}\right)$.

(v) The distribution in isotherms, streamlines and heatlines for the effect of Rayleigh numbers are partially similar to the effect of Darcy numbers.

\section{Acknowledgments}

This research was supported by the Development and Promotion of Science and Technology Talents Project (DPST) and by Department of Mathematics, Faculty of Science, Khon Kaen University, Khon Kaen, Thailand.

\section{References}

[1] T. Basak, S. Roy, S.K. Babu, Natural convection and flow in differentially heated isosceles triangular enclosures filled with porous medium, Chemical Engineering Science, 63, (2008), 3328-3340. DOI : 10.1016/j.ces.2008.03.038.

[2] Y. Varol, H.F. Oztop, M. Mobedi, I. Pop, Visualization of natural convection heat transport using heatline method in porous non-isothermally heated triangular cavity, International Journal of Heat and Mass Transfer, 51, (2008), 5040-5051. DOI : 10.1016/j.ijheatmasstransfer.2008.04.023.

[3] Y. Varol, Natural convection in divided trapezoidal cavities filled with fluid saturated porous media, International Communications in Heat and Mass Transfer, 37, (2010), 1350-1358. DOI : 10.1016/j.icheatmasstransfer.2010.07.010.

[4] P. Sompong, S. Witayangkurn, Natural convection in a trapezoidal enclosure with wavy top surface, Journal of Applied Mathematics, 2013, (2013), 1-7. DOI : $10.1155 / 2013 / 840632$.

[5] W. Kalaoka, S. Witayangkurn, Natural convection in porous square cavities with discrete heat sources on bottom and side walls, Thai Journal of Mathematics, 12, (2014), 207-221. 
[6] P. Haese, M. Teubner, Heat exchange in an attic space, International Journal of Heat and Mass Transfer, 45, (2002), 4925-4936. DOI : 10.1016/S0017-9310(02)00208-9.

[7] Y. Su, J. Davidson, Natural convective flow and heat transfer in a collector storage with an immersed heat exchanger: numerical study, Journal of Solar Energy Engineering, 127, (2005), 324-332. DOI : 10.1115/ISEC200576004 .

[8] A. Jung, P. Fryer, Optimising the quality of safe food: computational modelling of a continuous sterilisation process, Chemical Engineering Science, 54, (1999), 717-730. DOI : 10.1016/S0009-2509(98)00278-4.

[9] F.P. Incropera, Convection heat transfer in electronic equipment cooling, Journal of Heat Transfer, 110, (1988), 1097-1111. DOI : $10.1115 / 1.3250613$.

[10] L.R. Mealey, J.H. Merkin, Steady finite Rayleigh number convective flows in a porous medium with internal heat generation, International Journal of Thermal Sciences, 48, (2009), 1068-1080. DOI : 10.1016/j.ijthermalsci.2008.10.008.

[11] V.A.F. Costa, A.C.M. Sousa, P. Vasseur, Natural convection in square enclosures filled with fluid-saturated porous media under the influence of the magnetic field induced by two parallel vertical electric currents, International Journal of Heat and Mass Transfer, 55, (2012), 7321-7329. DOI : 10.1016/j.ijheatmasstransfer.2012.07.063.

[12] N.H. Saeid, I. Pop, Non-Darcy natural convection in a square cavity filled with a porous medium, Fluid Dynamics Research, 36, (2005), 35-43. DOI : 10.1016/j.fluiddyn.2004.10.004.

[13] T. Basak, S. Roy, T. Paul, I. Pop, Natural convection in a square cavity filled with a porous medium: effects of various thermal boundary conditions, International Journal of Heat and Mass Transfer, 49, (2006), 14301441. DOI : 10.1016/j.ijheatmasstransfer.2005.09.018.

[14] T.R. Mahapatra, D. Pal, S. Mondal, Natural convection in a lid-driven square cavity filled with Darcy-Forchheimer porous medium in the presence of thermal radiation, International Journal of Nonlinear Science, 11, (2011), 366-379. 
[15] N. Nithyadevi, P. Kandaswamy, J. Lee, Natural convection in a rectangular cavity with partially active side walls, International Journal of Heat and Mass Transfer, 50, (2007), 4688-4697. DOI : 10.1016/j.ijheatmasstransfer.2007.03.050.

[16] Y. Varol, H.F. Oztop, I. Pop, Natural convection in right-angle porous trapezoidal enclosure partially cooled from inclined wall, International Journal of Heat and Mass Transfer, 36, (2009), 6-15. DOI : 10.1016/j.icheatmasstransfer.2008.09.010.

[17] M. Mobedi, B. Sunden, Ü. Özkol, Visualization of diffusion and convection heat transport in a square cavity with natural convection, International Journal of Heat and Mass Transfer, 53, (2010), 99-109. DOI : 10.1016/j.ijheatmasstransfer.2009.09.048.

[18] H.F. Oztop, Natural convection in partially cooled and inclined porous rectangular enclosures, International Journal of Thermal Sciences, 46 , (2007), 149-156. DOI : 10.1016/j.ijthermalsci.2006.04.009.

[19] M.M. El-refaee, M.M. Elsayed, N.M. Al-najem, A.A. Noor, Natural convection in partially cooled tilted cavities, International Journal for Numerical Methods in Fluids, 28, (1998), 477-499. DOI : 10.1002/(SICI)10970363(19980915)28:3.

[20] P. Alam, S.R. Ansari, R. Kumar, Numerical study on natural convection in a porous cavity due to patial heating and cooling at vertical walls, International Journal of Applied Mathematics and Mechanics, 7, (2011), $1-21$.

[21] N. Nithyadevi, P. Kandaswamy, S. sivasankaran, Natural convection in a square cavity with partially active vertical walls: Time-periodic boundary condition, Mathematical Problems in Engineering, 2006, (2006), 1-16. DOI : 10.1155/MPE/2006/23425.

[22] W. Pakdee, P. Rattanadecho, Numerical analysis of natural convection in porous cavity with partial convective cooling condition, Journal of Porous Media, 12, (2009), 1083-1100. DOI : 10.1615/JPorMedia.v12.i11.50.

[23] M. Sathiyamoorthy, T. Basak, S. Roy, I. Pop, Steady natural convection flow in a square cavity filled with a porous medium for linearly heated side wall(s), International Journal of Heat and Mass Transfer, 50, (2007), 1892-1901. DOI : 10.1016/j.ijheatmasstransfer.2006.10.010. 
[24] J.N. Reddy, An introduction to the finite element method, McGraw-Hill, New York (1993).

[25] S. Roy, T. Basak, Finite element analysis of natural convection flows in a square cavity with non-uniformly heated wall(s), International Journal of Heat and Mass Transfer, 43, (2005), 668-680.

[26] S. Kimura, A. Bejan, The heatline visualization of convective heat transfer, Journal of Heat Transfer-Transactions of the ASME, 105, (1983), 916-919. DOI : $10.1115 / 1.3245684$.

\section{Appendix A}

\section{Nomenclature}

$\begin{array}{ll}D & \text { cold length } \\ D a & \text { Darcy number } \\ g & \text { acceleration due to gravity, } m^{-2} \\ K & \text { permeability of porous medium, } m^{2} \\ L & \text { length of square enclosure, } m \\ p & \text { pressure, } P a \\ P & \text { dimensionless pressure } \\ P r & \text { Prandtl number } \\ R a & \text { Rayleigh number } \\ T & \text { temperature, } K \\ T_{h} & \text { temperature of the left heated wall, } K \\ T_{c} & \text { temperature of the partially cooled wall, } K \\ u, v & \text { velocity components in } x \text { and } y \text { directions, } \\ U, V & \text { respectively, } m s^{-1} \\ & \text { dimensionless velocity components in } X \text { and } Y \\ x, y & \text { directions, respectively } \\ X, Y & \text { Cartesian coordinates along the horizontal and } \\ \text { Greek letters } & \text { vertical walls of the enclosure, } m \\ \alpha & \text { dimensionless Cartesian coordinates } \\ \beta & \text { thermal diffusivity, } m^{2} s^{-1} \\ \gamma & \text { volume expansion coefficient, } K^{-1} \\ & \text { penalty parameter }\end{array}$




$\begin{array}{ll}\theta & \text { dimensionless temperature } \\ \nu & \text { kinematic viscosity, } \mathrm{m}^{2} \mathrm{~s}^{-1} \\ \rho & \text { density, } \mathrm{kgm}^{-3} \\ \psi & \text { stream function } \\ \Pi & \text { heat function } \\ \text { Subscripts } & \\ c & \text { cold } \\ h & \text { hot }\end{array}$

